\title{
ANALISIS LAPORAN KEUANGAN MASJID BERDASARKAN PSAK NO. 45 TENTANG PELAPORAN KEUANGAN ORGANISASI NIRLABA (STUDI KASUS DI MASJID AGUNG NURUL HUDA SUMBAWA BESAR)
}

\author{
Analysis of Mosque Financial Statements Based on SFAS No. 45 About Nonprofit Financial \\ Reporting at the Sumbawa Besar Nurul Huda Great Mosque
}

\author{
Diah Intan Syahfitri, S.E.,M.Acc ${ }^{1}$, Viki Ulandari, S.Ak ${ }^{1}$ \\ ${ }^{1}$ Akuntansi, Ekonomi dan Bisnis, Universitas Teknologi Sumbawa
}

E-mail: Diahintan16@gmail.com

\begin{abstract}
This research aims to determine the financial statements of the Nurul Huda Sumbawa Grand Mosque and to determine the suitability of the financial statements of the Nurul Huda Grand Mosque with SFAS No. 45. The method used in this study is a qualitative method with a descriptive approach. Sources of data use primary and secondary data collected by using observation, interview, and documentation techniques. In this study the authors conducted data analysis by collecting, reducing, presenting, and analyzing data so that conclusions can be drawn. The results showed that the financial statements of the Nurul Huda Grand Mosque were not in accordance with SFAS No. 45 because still uses a simple format in the form of a financial accountability report prepared by the previous management.
\end{abstract}

Key words: Mosque Financial Report, SFAS No.45

\begin{abstract}
ABSTRAK
Penelitian ini bertujuan untuk mengetahui laporan keuangan Masjid Agung Nurul Huda Sumbawa dan untuk menganalisis kesesuaian laporan keuangan Masjid Agung Nurul Huda dengan PSAK No. 45. Metode yang digunakan dalam penelitian ini adalah metode kualitatif dengan pendekatan deskriptif. Sumber data menggunakan data primer dan sekunder yang dikumpulkan dengan menggunakan teknik observasi, wawancara, dan dokumentasi. Dalam penelitian ini penulis melakukan analisis data dengan cara mengumpulkan, mereduksi, menyajikan, dan menganalisis data hingga dapat ditarik sebuah kesimpulan. Hasil penelitian menunjukkan bahwa laporan keuangan Masjid Agung Nurul Huda belum sesuai dengan PSAK No. 45 karena masih menggunakan format sederhana berbentuk laporan pertanggunngjawaban keuangan yang disusun oleh pengurus terdahulu.
\end{abstract}

Kata Kunci: Laporan Keuangan Masjid, PSAK No.45

\section{Pendahuluan}

Masjid sangat erat kaitannya dengan kegiatan keagamaan, karena masjid merupakan pusat peradaban bagi umat Islam. Di Indonesia, jumlah penduduk muslim sangat besar dan menjadi mayoritas dari penduduk yang memeluk agama selain islam. Sesuai dengan data perhitungan Badan Pusat Statistik pada Sensus Penduduk tahun 2010, jumlah penduduk muslim di Indonesia sebesar 207.176.162 jiwa atau sebesar 87,18\% dari jumlah penduduk Indonesia yaitu 237.641.326 jiwa.

Andarsari (2016) menyatakan bahwa masjid tergolong sebagai organisasi nirlaba yang penghimpunan dananya tidak bertujuan untuk mencari keuntungan tetapi untuk mensejahterakan umat. Dengan fungsi masjid sebagai pengelola dana umat maka diperlukan sebuah sistem akuntansi yang handal untuk menjamin akuntabilitasnya. Oleh karena itu organisasi nirlaba dituntut untuk memberikan informasi dalam suatu laporan pertanggungjawaban kepada publik atas pengelolaan sejumlah dana yang diterima dari masyarakat dalam bentuk laporan keuangan seperti halnya yang dilakukan oleh organisasi yang berorientasi laba.
Berdasarkan Surat Keputusan Direktorat Urusan Agama Islam dan Pembinaan Syariah Direktorat Jenderal Bimbingan Masyarakat Islam Kementerian Agama Republik Indonesia nomor DJ.II/802 Tahun 2014 tentang Standar Pembinaan Manajemen Masjid yang dikeluarkan pada Februari 2015, mengatur tentang tipologi masjid yang terdiri dari: Masjid Negara, Masjid Nasional, Masjid Raya, Masjid Agung, Masjid Besar, Masjid Jami, Masjid bersejarah, dan Masjid ditempat publik. Namun di Kabupaten Sumbawa hanya terdapat masjid dengan empat tipologi yaitu tipologi masjid jami sebesar 447 masjid, tipologi masjid di tempat publik sebesar 57 masjid, tipologi masjid besar sebesar 11 masjid, dan tipologi masjid bersejarah hanya 1 masjid yaitu Masjid Agung Nurul Huda.

Masjid Agung Nurul Huda termasuk dalam tipologi masjid bersejarah karena merupakan masjid yang sudah berdiri sejak zaman kerajaan Sumbawa yaitu pada tahun 1648 dan dijadikan sebagai masjid kerajaan. Selain itu, Masjid Agung Nurul Huda merupakan masjid yang berstatus sebagai masjid kabupaten. Hal ini menunjukkan bahwa Masjid Agung Nurul Huda merupakan masjid terbesar dan terluas di Kabupaten Sumbawa 
dengan luas tanah sebesar $6.000 \mathrm{~m}^{2}$ dan luas bangunan sebesar $2.304 \mathrm{~m}^{2}$. Masjid Agung Nurul Huda sendiri dapat menampung hingga 3.000 jemaah. Besarnya jemaah tersebut tentu berbanding lurus dengan rata-rata pendapatan yang didapat masjid yaitu sebesar Rp11.000.000 per pekan. Hal ini terjadi karena salah satu sumber utama pendapatan masjid yaitu brerasal dari kotak amal, infaq, serta sadaqah para jemaah dan masyarakat. Karena pendapatan masjid bersumber dari masyarakat maka seluruh kegiatan masjid wajib dipertanggungjawabkan, terutama dalam hal pengelolaan keuangan megingat besarnya pendapatan yang diterima masjid setiap pekannya. Sehingga harus dilakukan pencatatan serta pelaporan yang baik dan sesuai dengan standar pelaporan keuangan berdasarkan PSAK No. 45 .

PSAK No. 45 (2011) Menyebutkan pengguna laporan keuangan memiliki kepentingan bersama yang tidak berbeda dengan organisasi bisnis, yaitu untuk menilai: (a) jasa yang diberikan oleh organisasi nirlaba dan kemampuannya untuk terus memberikan jasa tersebut; (b) cara manajer melakukan tanggung jawab dan aspek kinerjanya. Kemudian PSAK No. 45 mensyaratkan organisasi nirlaba untuk menyediakan seperangkat laporan keuangan lengkap yang meliputi laporan posisi keuangan, laporan aktivitas, laporan arus kas, dan catatan atas laporan keuangan.

Oleh karena itu, pembuatan laporan keuangan masjid sangat penting karena dari laporan keuangan tersebut akan menampilkan dan menunjukkan bagaimana pengelolaan keuangan yang telah dilakukan. Disamping itu pertanggungjawaban keuangan menjadi jelas dan dapat meningkatkan kepercayaan para jemaah masjid yang telah memberikan sumbangan. Sebagai organisasi yang menggunakan dana masyarakat sebagai sumber keuangannya, berarti masjid menjadi bagian entitas publik yang seluruh aktivitasnya harus dipertanggungjawabkan kepada publik. Proses masuk dan keluarnya dana memerlukan pencatatan dan pelaporan yang baik dan sesuai dengan standar pelaporan keuangan, dalam hal ini sesuai dengan Pernyataan Standar Akuntansi Keuangan (PSAK) No. 45 tentang Pelaporan Keuangan Organisasi Nirlaba.

Beberapa penelitan yang telah dilakukan yang berkaitan dengan penerapan PSAK No. 45 menunjukkan bahwa laporan keuangan organisasi nirlaba tersebut masih belum sesuai dengan PSAK No. 45. Seperti penelitian yang dilakukan oleh Pontoh (2013) dengan judul "Penerapan Laporan Keuangan Organisasi Nirlaba berdasarkan PSAK No. 45 pada Gereja BZL". Hasil dari penelitian ini menyatakan bahwa laporan keuangan yang ada di Gereja Bukit Zaitun menyusun laporan keuangan sesuai dengan Tata Dasar dan Peraturan Gereja, hal ini berarti Gereja Bukit Zaitun belum menerapkan penyusunan laporan keuangan yang sesuai dengan format laporan keuangan nirlaba yang ada pada PSAK No. 45. Laporan keuangan yang diterbitkan pada setiap jemaat berupa laporan realisasi anggaran. Penelitian selanjutnya juga dilakukan oleh Rizky dan Padmono (2013) yang berjudul "Analisis Penerapan PSAK No. 45 Pada Yayasan Masjid Al-Falah Surabaya”. Hasil dari penelitian ini menunjukkan bahwa laporan keuangan telah disajikan sesuai dengan PSAK No. 45, tetapi terdapat sebagian akun yang belum disajikan sesuai dengan PSAK No. 45 yaitu klasifikasi aset bersih.

\section{Metode}

Metode yang digunakan dalam penelitian ini adalah metode deskriptif kualitatif yang bertujuan untuk mengungkapkan kejadian atau fakta saat penelitian berlangsung dengan menyuguhkan dan mendeskripsikan apa yang sebenarnya terjadi. Lokasi dalam penelitian ini adalah Masjid Agung Nurul Huda Sumbawa Besar. Sumber data yang digunakan dalam penelitian ini yaitu data primer dan data sekunder. Tahapan yang dilakukan peneliti dalam menganalisis data adalah: (1) Pengumpulan data yang diperoleh dari wawancara, observasi, dan dokumentasi di lokasi penelitian; (2) Mereduksi data dengan memfokuskan pada data-data yang berkenaan dengan pelaporan keuangan di Masjid Agung Nurul Huda Sumbawa; (3) Penyajian data dalam bentuk teks yang bersifat naratif; (4) Menganalisis laporan keuangan Masjid Agung Nurul Huda berdasarkan PSAK No. 45; (5) Penarikan Kesimpulan.

\section{Hasil Penelitian}

Laporan Keuangan Masjid Agung Nurul Huda Sumbawa Besar

Penyusunan laporan pertanggungjawaban keuangan pada Masjid Agung Nurul Huda memiliki beberapa tahapan, diantaranya yaitu:

\section{a. Penghitungan Kotak Amal}

Kotak amal merupakan sumber penerimaan utama bagi Masjid Agung Nurul Huda Sumbawa Besar. Selain kotak amal, penerimaan masjid juga berasal dari infaq para jemaah maupun masyarakat. Kotak amal dihitung oleh pengurus masjid pada hari Jumat setelah para jemaah selesai melaksanakan shalat Jumat.

b. Pengisian Berita Acara Penghitungan Kotak Amal Masjid

Berita acara penghitungan kotak amal masjid berisikan jumlah penerimaan masjid yang berasal dari kotak amal Jumat, Maghrib, dan Subuh serta infaq para jemaah maupun masyarakat, dan pengeluaran masjid. Pengeluaran masjid dalam berita acara biasanya dilaporkan berupa nota dan kuitansi, karena untuk sementara waktu pembelian atau pembayaran telah dilakukan menggunakan kas kecil yang nantinya akan digantikan kembali dengan penerimaan masjid setelah penghitungan kotak amal selesai. Sehingga pada berita acara hanya dituliskan jumlah dari nota yang ada dan total pengeluarannya, tidak dirincikan dipergunakan untuk keperluan apa saja pengeluaran tersebut. Kemudian penerimaan yang telah dijumlahkan, akan dikurangkan dengan jumlah pengeluaran. Sehingga akan diketahui penerimaan bersih pada minggu tersebut.

c. Penyusunan dan Pengumuman Laporan Pertanggungjawaban Keuangan

Laporan pertanggungjawaban keuangan Masjid Agung Nurul Huda disusun oleh bendahara masjid. Penyusunan laporan tersebut dilakukan satu minggu sekali yang mengacu pada berita acara penghitungan kotak amal masjid. Laporan pertanggungjawaban keuangan berisikan jumlah kas minggu lalu, jumlah penerimaan minggu ini, jumlah pengeluaran minggu ini, dan jumlah kas akhir. Selanjutnya laporan pertanggungjawaban tersebut diumukan setiap hari Jumat tepat sebelum shalat Jumat dilaksanakan. 
Laporan Keuangan Masjid Agung Nurul Huda Berdasarkan PSAK No. 45

Penyusunan laporan keuangan Masjid Agung Nurul Huda masih menggunakan format pengurus terdahulu dan belum sesuai dengan PSAK No. 45. Berikut merupakan laporan keuangan Masjid Agung Nurul Huda pada bulan Oktober sampai dengan Desember 2017 yang disusun berdasarkan standar pelaporan keuangan sesuai dengan PSAK No. 45, antara lain:

\section{Laporan Posisi Keuangan}

Tabel 1. Laporan Posisi Keuangan Masjid Agung Nurul Huda Sumbawa Besar

\begin{tabular}{l} 
MASJID AGUNG NURUL HUDA SUMBAWA \\
\multicolumn{1}{c}{ BESAR } \\
\multicolumn{1}{c}{ LAPORAN POSISI KEUANGAN } \\
\multicolumn{1}{c}{ YANG BERAKHIR PADA TANGGAL 31 } \\
DESEMBER 2017 \\
\hline ASET \\
Aset Lancar \\
Kas dan Setara Kas \\
201.455.939 \\
Aset Tidak Lancar \\
Aset Tetap \\
3.662.814.390 \\
Jumlah Aset \\
3.864.270.329 \\
KEWAJIBAN DAN ASET NETO \\
Kewajiban \\
- \\
Aset Tidak Terikat \\
201.455.939 \\
Aset Terikat Temporer \\
128.314.390 \\
Aset Terikat Permanen \\
3.534.500.000 \\
Jumlah Kewajiban dan Aset Neto \\
3.864.270.329
\end{tabular}

a. Aset

Kas dan setara kas yang disajikan dalam laporan posisi keuangan merupakan jumlah dari aset bersih pada akhir periode. Selain memiliki aset berupa kas dan setara kas, Masjid Agung Nurul Huda Sumbawa Besar juga memiliki aset tetap terdiri dari tanah, bangunan, dan peralatan.

b. Kewajiban dan Aset Neto

Masjid Agung Nurul Huda tidak memiliki kewajiban kepada pihak lain seperti utang, karena pembelian dan pembayaran yang dilakukan oleh pengurus masjid selalu secara tunai. Aset yang dimiliki Masjid Agung Nurul Huda yaitu aset tidak terikat yang terdiri dari sumbangan dan infaq para jemaah masjid, aset terikat temporer yang terdiri dari peralatan masjid, dan aset terikat permanen yang terdiri dari tanah dan bangunan masjid.

\section{Laporan Aktivitas}

Tabel 2. Laporan Aktivitas Masjid Agung Nurul Huda Sumbawa Besar

\begin{tabular}{l} 
MASJID AGUNG NURUL HUDA SUMBAWA \\
BESAR \\
UNTUK TAHUN YANG BERAKHIR PADA \\
\multicolumn{1}{c}{ TANGGAL 31 DESEMBER 2017 } \\
PERUBAHAN ASET NETO TIDAK TERIKAT \\
Pendapatan \\
Sumbangan \\
134.320.000 \\
Lain-lain \\
200.000 \\
Jumlah \\
134.520.000 \\
Beban \\
Sumbangan untuk muslim Palestina \\
12.825.000 \\
Biaya Honorarium \\
Biaya kesejahteraan pengurus \\
masjid/honor pengurus \\
45.300.000 \\
Biaya transportasi petugas pengkajian \\
dan pengembangan agama islam \\
dan tenaga lainnya \\
12.400.000 \\
Biaya Operasional \\
Biaya ATK \\
427.500 \\
Biaya listrik, air, telepon \\
5.538.500 \\
Biaya perbaikan dan pemeliharaan peralatan \\
3.839.000 \\
Biaya perbaikan dan pemeliharaan bangunan \\
39.912.000 \\
Biaya BBM \\
237.000 \\
Biaya konsumsi \\
868.000 \\
Biaya lain-lain \\
5.111.788 \\
Biaya Peralatan \\
Biaya pembelian etalase Quran dan \\
batang pipa 1 buah mixer merk yamaha \\
3.951.500 channel) \\
Biaya Pasang wifi dan facum cleane \\
6.769.890 \\
\hline
\end{tabular}


Beli satu paket komputer merk acer

5.200.000

Beli karpet turkey sebanyak 180 meter

untuk 6 shaf depan

90.040 .000

Beli 1 buah gerobak

987.000

Beli 1 unit etalase uk 50x120x180

2.150.000

Beli 1 unit televisi panasonic 43 inch

dan ongkos kirim

4.114.000

Beban Perlengkapan

Beli alat kebersihan tempat wudu

320.000

Bayar langganan buletin dakwah jumat

dan beli baygon

306.500

Beli alat kebersihan masjid

1.005.000

Jumlah

256.404.678

Kenaikan (Penurunan) aset neto

tidak terikat

(121.884.678)

PERUBAHAN ASET NETO

TERIKAT TEMPORER

128.314.390

PERUBAHAN ASET NETO

TERIKAT PERMANEN

3.534.500.000

KENAIKAN ASET NETO

3.540.929.712

ASET NETO AWAL PERIODE

323.340.617

ASET NETO AKHIR PERIODE

3.864.270.329

a. Pendapatan dan Penghasilan Tida Terikat

Dalam laporan aktivitas Masjid Agung Nurul Huda Sumbawa menyajikan pendapatan dan penghasilan tidak terikat yang terdiri dari sumbangan dan penerimaan lain.

b. Beban

Beban yaitu seluruh penggunaan dana untuk membiayai program setiap kegiatan dan pengalokasian dana, serta untuk biaya-biaya lain. Beban yang terdapat pada Masjid Agung Nurul Huda yaitu sumbangan untuk muslim Palestina, beban honorarium, beban operasional, beban peralatan, dan beban perlengkapan.

c. Kenaikan dan Penurunan Aset Neto

Kenaikan dan penurunan aset neto ditentukan oleh hasil penghitungan jumlah pendapatan dan jumlah beban. Jika jumlah pendapatan lebih besar dari jumlah beban, maka terjadi kenaikan pada aset neto. Sebaliknya, jika jumlah pendapatan lebih kecil dari jumlah beban maka terjadi penurunan. Pada Masjid Agung Nurul Huda jumlah pendapatan lebih kecil dari jumlah beban, sehingga pada bulan Oktober sampai dengan Desember 2017 terjadi penurunan aset neto.

d. Perubahan Aset Neto Terikat Temporer

Aset terikat temporer merupakan aset yang harus dipertahankan sampai dengan periode tertentu atau sampai dengan terpenuhinya keadaan tertentu. Aset terikat temporer yang terdapat pada Masjid Agung Nurul Huda berupa peralatan.

e. Perubahan Aset Neto Terikat Permanen

Aset terikat permanen merupakan aset yang harus dipertahankan secara permanen. Aset permanen yang terdapat pada Masjid Agung Nurul Huda berupa tanah dan bangunan masjid.

f. Aset Neto Akhir Periode

Aset neto akhir periode merupakan hasil akhir dari laporan aktivitas. Jumlah aset neto akhir periode ditentukan dari hasil penghitungan jumlah kenaikan atau penurunan aset neto dengan jumlah perubahan aset neto terikat temporer, perubahan aset neto terikat permanen, dan jumlah aset neto awal periode.

3. Laporan Arus Kas

Tabel 3. Laporan Arus Kas Masjid Agung Nurul Huda Sumbawa Besar

\author{
MASJID AGUNG NURUL HUDA SUMBAWA \\ BESAR \\ LAPORAN ARUS KAS \\ UNTUK TAHUN YANG BERAKHIR PADA \\ TANGGAL 31 DESEMBER 2017
}




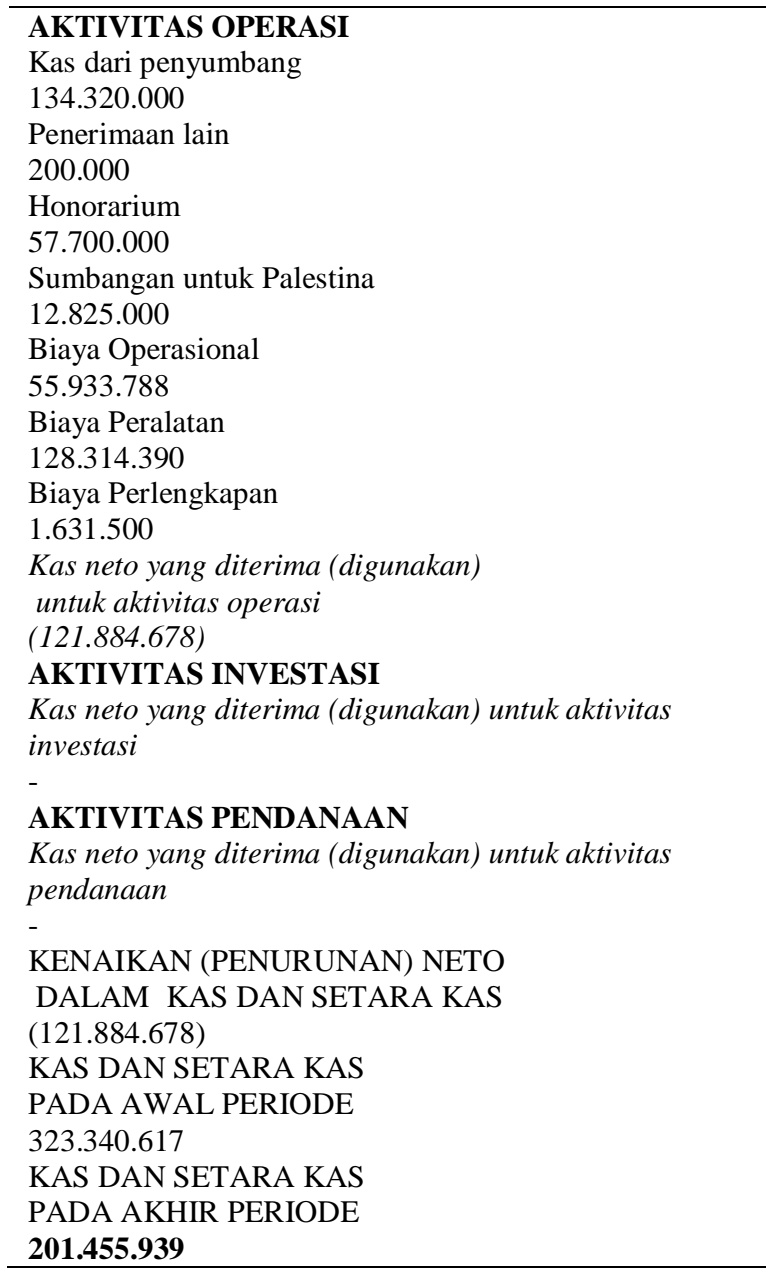

a. Arus Kas dari Aktivitas Operasi

Akun-akun yang disajikan adalah penambahan dan pengurangan kas yang terkait dengan kegiatan pengelolaan Masjid Agung Nurul Huda berupa penerimaan dari penyumbang, penerimaan lain, honorarium, sumbangan untuk Palestina, biaya operasional, biaya peralatan, dan biaya perlengkapan. Hasil akhir dari arus kas aktivitas operasi ditentukan oleh selisih jumlah pendapatan dengan jumlah pengeluaran.

b. Arus Kas dari Aktivitas Investasi

Akun yang disajikan yaitu semua penerimaan dan pengeluaran kas yang terkait dengan investasi Pengelolaan Masjid Agung Nurul Huda Sumbawa Besar. Dalam hal ini Masjid Agung Nurul Huda tidak mempunyai akun yang terkait dengan aktivitas investasi.

c. Arus Kas dari Aktivitas Pendanaan

Akun yang disajikan yaitu penerimaan dan pengeluaran kas terkait dengan pendanaan. Tetapi Masjid Agung Nurul Huda tidak mempunyai akun yang terkait dengan aktivitas pendanaan.

d. Kenaikan dan Penurunan Neto dalam Kas dan Setara Kas
Kenaikan dan penurunan neto dalam kas dan setara kas ditentukan oleh hasil penghitungan jumlah kas neto aktivitas operasi, kas neto aktivitas investasi, dan kas neto aktivitas pendanaan. Pada Masjid Agung Nurul Huda tidak ada kas dari aktivitas investasi dan pendanaan, sehingga hanya kas dari aktivitas operasi yang digunakan. Hal ini berarti Masjid Agung Nurul Huda mengalami penurunan neto dalam kas dan setara kas.

e. Kas dan Setara Kas Pada Akhir Periode

Kas dan setara kas pada akhir periode merupakan hasil akhir dari laporan aktivitas. Jumlahnya ditentukan oleh hasil penghitungan kenaikan atau penurunan neto dalam kas dan setara kas dengan kas dan setara kas pada awal periode.

4. Catatan Atas Laporan Keuangan

Tabel 4. Catatan Atas Laporan Keuangan Masjid Agung Nurul Huda Sumbawa Besar

MASJID AGUNG NURUL HUDA SUMBAWA
BESAR
CATATAN ATAS LAPORAN KEUANGAN
UNTUK TAHUN YANG BERAKHIR PADA
TANGGAL 31 DESEMBER 2017
CATATAN A
Pengelola Masjid Agung Nurul Huda hanya memiliki
penerimaan tidak terikat. Hal ini karena seluruh
penerimaan baik yang berasal dari kotak amal maupun
infaq para penyumbang dikumpulkan menjadi satu
kesatuan, kemudian digunakan untuk membiayai seluruh
pengeluaran yang terjadi.
CATATAN B
Penerimaan lain:
Setor kembali Sisa Pengerjaan
200.000 Atap
Penerimaan diperoleh dari kelebihan pembayaran atas
biaya yang dikeluarkan pada 10 November 2017 untuk
pembangunan atap penghubung dari kamar mandi wanita
ke masjid. Penerimaan kelebihan pembayaran ini diterima
pada 15 Desember 2017.

Catatan atas laporan keuangan Masjid Agung Nurul Huda berupa:

a. Kebijakan Pengurus Masjid

b. Catatan Penerimaan Lain Masjid

\section{Kesimpulan}

Berdasarkan hasil penelitian terhadap analisis laporan keuangan masjid berdasarkan PSAK No. 45 pada Masjid Agung Nurul Huda Sumbawa Besar, maka penulis menyimpulkan bahwa:

1. Laporan keuangan Masjid Agung Nurul Huda menggunakan format yang telah disusun oleh pengurus sebelumnya dalam bentuk laporan pertanggungjawaban keuangan. Sehingga laporan keuangan Masjid Agung Nurul Huda belum sesuai dengan PSAK No. 45. Hal ini karena pengurus khususnya bendahara belum mengetahui mengenai PSAK No. 45 yang mengatur tentang Pelaporan Keuangan Organisasi Nirlaba. 
2. Laporan keuangan Masjid Agung Nurul Huda hanya menyajikan posisi kas minggu lalu, penerimaan dan pengeluaran minggu ini, dan jumlah kas akhir. Berbeda dengan PSAK No. 45 yang menyajikan empat laporan keuangan yaitu laporan posisi keuangan, laporan aktivitas, laporan arus kas, dan catatan atas laporan keuangan.

3. Penyusunan laporan keuangan Masjid Agung Nurul Huda yang telah disusun dan disesuaikan berdasarkan PSAK No. 45 membuktikan bahwa pelaporan keuangan organisasi nirlaba yang diatur dalam PSAK No. 45 menjadikan laporan keuangan Masjid Agung Nurul Huda lebih mudah dipahami, memiliki relevansi, dan memiliki daya banding yang tinggi.

4. Hasil penelitian pada Masjid Agung Nurul Huda Sumbawa sesuai dengan hasil penelitian terdahulu yang dilakukan oleh Chenly Ribka S. Pontoh tahun 2013 dengan judul "Penerapan Laporan Keuangan Organisasi Nirlaba Berdasarkan Psak No 45 Pada Gereja Bzl", Tantri Sofyana Putri tahun 2015 dengan judul "Analisis Penerapan Pernyataan Standar Akuntansi Keuangan Nomor 45 Pada Gereja Huria Kristen Batak Protestan (Hkbp) Kertanegara Semarang", dan Andi Marlinah dan Ali Ibrahim tahun 2018 dengan judul "Penerapan Laporan Keuangan Organisasi Nirlaba Berdasarkan Psak No. 45 (Studi Masjid Al-Markaz Al-Islami Jenderal M. Jusuf)". Menunjukkan bahwa penyusunan laporan keuangan pada masing-masing objek penelitian belum sesuai dengan PSAK No. 45 karena penyusunan laporan keuangan meggunakan format yang telah disusun oleh pengurus terdahulu.

\section{Saran}

1. Saran yang diberikan oleh penulis terhadap Masjid Agung Nurul Huda yaitu:

a. Sebaiknya pembuatan laporan keuangan masjid mengacu pada PSAK No. 45 dan dibuat minimal satu bulan sekali untuk mempermudah pengurus masjid. Karena akan menghasilkan laporan keuangan yang jelas dan rinci.

b. Merincikan dengan baik anggaran atau pengeluaran. Meskipun terdapat nota atau kuitansi, akan lebih baik jika dicatat dengan rinci pada laporan keuangan.

2. Keterbatasan yang terdapat dalam penelitian ini adalah pada data yang diperoleh oleh penulis untuk menyusun laporan keuangan sesusai dengan PSAK No. 45. Data yang diperoleh dalam penelitian hanya data keuangan bulan Oktober sampai dengan Desember 2017. Sehingga diharapkan bagi peneliti selanjutnya dapat memperoleh data satu tahun agar informasi keuangan menjadi lebih lengkap.

\section{Daftar Pustaka}

Andarsari, Pipit Rosita. (2016). Laporan Keuangan Organisasi Nirlaba (Lembaga Masjid). Jurnal Ekonomi Universitas Kediri. 1(2): 143-152. http://ojs.unikkediri.ac.id/index.php/ekonika/article/view/12. Diakses 1 Oktober 2018.
Andikawati, Desi dan Wahyu Agus Winarno. (2014). Financial Report of The Mosque Institute (The Case Study At Anaz Mahfudz and Al - Huda Mosque). Artikel Ilmiah Mahasiswa. 1-6. http://repository.unej.ac.id/bitstream/handle/123456 789/63110/Desy\%20Andikawati.pdf?sequence=1 . Diakses 1 Oktober 2018.

Ayub, Moh. E. dkk. (1996). Manajemen Masjid. Jakarta: Gema Insani Press.

Badan Pusat Statistik. (2010). Sensus Penduduk Indonesia. https://www.bps.go.id/. Diakses 30 September 2018.

Hery. (2016). Analisis Laporan Keuangan. Jakarta: Grasindo.

Ikatan Akuntansi Indonesia. (2011). Pernyataan Standar Akuntansi Keuangan No. 45 Tentang Pelaporan Keuanagn Entitas Nirlaba. Jakarta: Ikatan Akuntansi Indonesia.

Kementrian Agama Republik Indonesia. Diambil dari https://kemenag.go.id/berita/

Marlinah, Andi dan Ali Ibrahim. (2018). Penerapan Laporan Keuangan Organisasi Nirlaba Berdasarkan Psak No. 45. Akmen Jurnal ilmiah. 15(1): 1-19. https://ejurnal.stienobelindonesia.ac.id/index.php/a kmen/article/view/196. Dikases 1 Oktober 2018.

Pontoh, Chenly Ribka. (2013). Penerapan Laporan Keuangan Organisasi Nirlaba Berdasarkan PSAK No 45 pada Gereja Bzl. Unsrat Manado: Jurnal Emba. https://ejournal.unsrat.ac.id/index.php/emba/article/ view/1651. Diakses 2 Oktober 2018.

Purnama, Yusuf Adi. (2012). Financial Management And Financial Statements Of Great Mosque At-Taqwa Bondowoso (A Case Study of At-Taqwa Great Mosque, Bondowoso). Jurnal Akuntansi. 1(2): 1-10. http://digilib.unmuhjember.ac.id/files/disk1/45/. Diakses 1 Oktober 2018.

Putri, Tantri Sofyana. (2015). Analisis Penerapan Pernyatan Standar Akuntansi Keuangan Nomor 45 Pada Gereja Huria Kristen Batak Protestan (Hkbp) Kertanegara Semarang. http://eprints.dinus.ac.id/17634/. Diakses 3 Oktober 2018

Rizky, Diyani Ade dan Yazid Yud Padmono. (2013). Analisis Penerapan PSAK No. 45 Pada Yayasan Masjid AlFalah Surabaya. Jurnal Ilmu \& Riset Akuntansi, Vol. 2. No.7. https://ejournal.stiesia.ac.id/index/index. Diakses 2 Oktober 2018.

Simanjuntak, D. Anzar dan Januarsi. (2011). Akuntanbilitas dan Pengelolaan Keuangan di Masjid. Simposium Nasional AkuntansiXIV Aceh. 1(2): 1-30. http://ib.ibs.ac.id/materi/Prosiding/SNAXIV-Aceh/. Diakses 3 Oktober2018.

Sistem Informasi Masjid Kabupaten Sumbawa. Diambil dari http://simas.kemenag.go.id

Sugiyono. (2011). Metode Penelitian Kuantitatif Kualitatif dan $R \& D$. Bandung: ALFABETA. 
Jurnal Ekonomi dan Bisnis Indonesia

Wirjana, Bernardine R. (2007). Mencapai Manajemen Berkualitas : Organisasi, Kinerja, Program. Yogyakarta: Penerbit Andi 